\title{
Research on the Distribution Law and Influencing Factors of Ground Temperature in Xutuan Coal Mine
}

\author{
Lintao Wang, Qimeng Liu, Sen Yang \\ College of Earth and Environment, Anhui University of Science and Technology, Huainan, China \\ Email: Wanglt1995@foxmail.com
}

How to cite this paper: Wang, L. T., Liu, Q. M., \& Yang, S. (2020). Research on the Distribution Law and Influencing Factors of Ground Temperature in Xutuan Coal Mine. Journal of Geoscience and Environment Protection, 8, 88-101.

https://doi.org/10.4236/gep.2020.810006

Received: September 11, 2020

Accepted: October 16, 2020

Published: October 19, 2020

Copyright $\odot 2020$ by author(s) and Scientific Research Publishing Inc. This work is licensed under the Creative Commons Attribution International License (CC BY 4.0).

http://creativecommons.org/licenses/by/4.0/

\begin{abstract}
Taking the Xutuan coal mine as an example, based on the temperature measurement data, combined with the geological background of the study area, this paper analyzes the distribution, thermal evolution, formation mechanism and influencing factors of the deep geothermal field in the study area. Combined with previous research results and field temperature measurement data, the research results show that the temperature gradient of Xutuan coal mine varies in the range of $2.65^{\circ} \mathrm{C} / \mathrm{hm}-3.15^{\circ} \mathrm{C} / \mathrm{hm}$, most of which are $1.6^{\circ} \mathrm{C} / \mathrm{hm}$ $3.0^{\circ} \mathrm{C} / \mathrm{hm}$, which belongs to the normal area with relatively stable geothermal gradient. The northern part of the study area is more developed than the southern part. The minimum geothermal gradient is $2.65^{\circ} \mathrm{C} / \mathrm{hm}$, and the geothermal gradient gradually increases from north to south; the geothermal gradient is negatively correlated with the buried depth within a certain depth range. Roughly taking the depth of $200-350 \mathrm{~m}$ as the dividing line, the temperature increases with the increase of depth, showing a good linear trend and the characteristics of conductive heating. The main influencing factor of the geothermal field in the study area is the geological structure, which is greatly affected by the fault structure. Followed by lithological changes and groundwater activities, the flow of the four waters has a certain control effect on the shallow geothermal field distribution.
\end{abstract}

\section{Keywords}

Geothermal Distribution, Xutuan Coal Mine, Geothermal Gradient, Influencing Factors, Geological Structure

\section{Introduction}

With the increase in Chinese energy demand, coal resources have shifted from 
shallow mining to deep mining. The problem of mine thermal damage caused by the continuous rise of ground temperature has also become more severe, which greatly restricts the safe production of mines (Luo, Ju, \& Tan, 2011; Peng, Wu, \& Peng, 2015; Yao \& Pang, 2018; Cui \& Ren, 2011). Geothermal has become an urgent problem to be solved in production and construction, and it has attracted widespread scholars' attention. Predecessors have conducted many discussions on the geothermal field characteristics of coal fields, but most of them are limited to shallow coal seams. Research on deep mines, especially coal seams with a buried depth of more than $1000 \mathrm{~m}$, is relatively weak. Although the coal mining history of Xutuan coal mine has reached decades, there are few scientific research results in the field of coal geothermal field. Therefore, the analysis and study of the geothermal field in the middle and deep part of Xutuan coal mine can provide basic data for the prevention and control of geothermal disasters in mines on the one hand, and provide scientific basis for analyzing the thermal evolution process of coal seams and the structural distribution characteristics of coal fields on the other hand ( $\mathrm{Li} \& \mathrm{Li}, 2010$; Lin et al., 2015).

\section{Geological Background}

Xutuan coal mine is located in Xutuan Town, Mengcheng County, Anhui Province, in the southwest of Linhuan mining area in Huaibei Coalfield, east of Yuhuai fold belt, and central and southern Xusu arc nappe structure (in China). Due to the superimposition of multiple tectonic movements, the large east-west faults and the large north-north-east faults in the area criss-cross, forming many near-network fault-block structures (Figure 1). The strike length of the well is 10 - $13 \mathrm{~km}$, the slant width is $3-7 \mathrm{~km}$, and the area is about $52 \mathrm{~km}^{2}$. The average coal seam thickness is $15.8 \mathrm{~m}$.

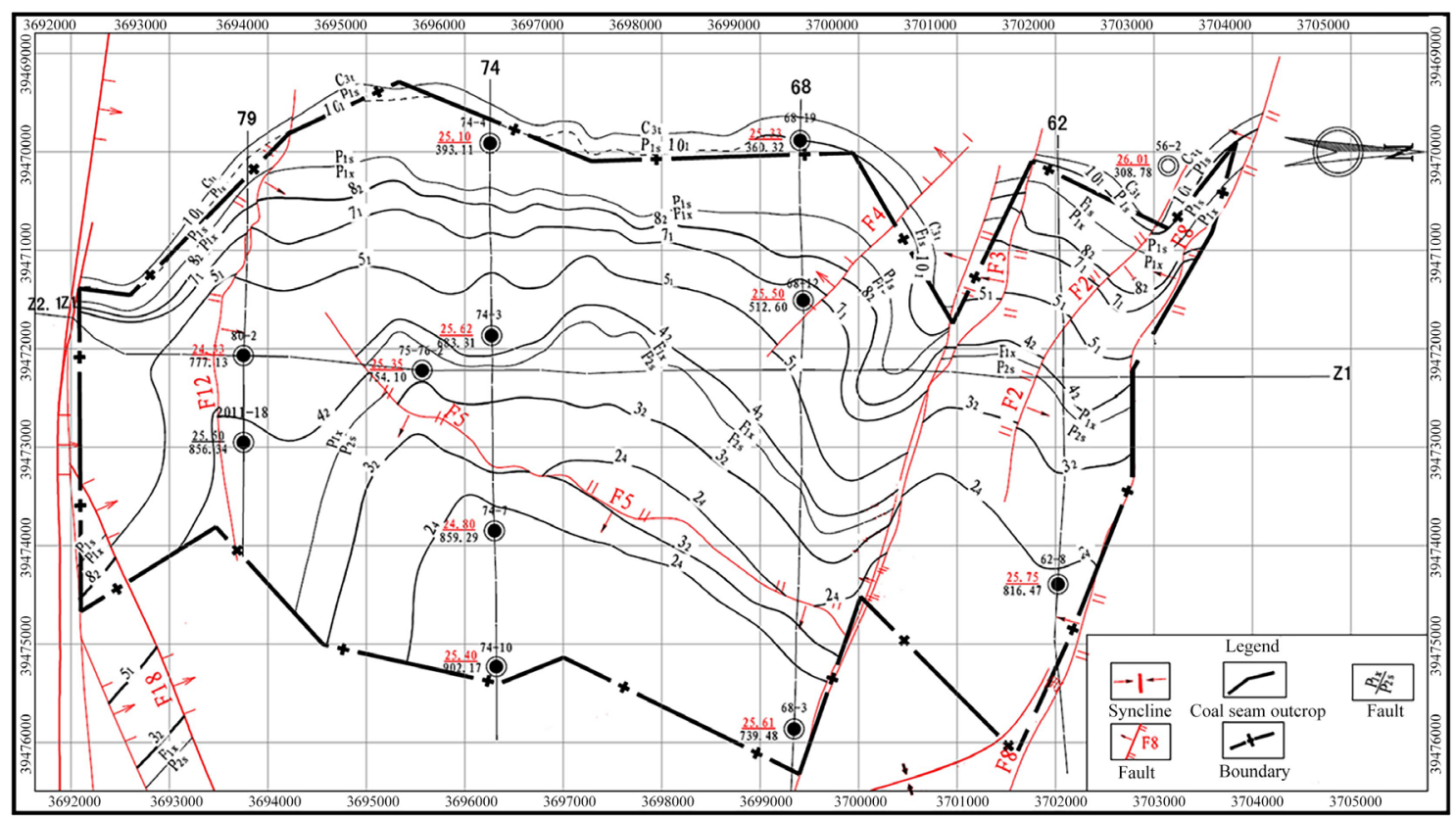

Figure 1. Structural outline of Xutuan coal mine. 
The geological reserves of the well are 480.311 million tons and the recoverable reserves are 217.41 million tons. The terrain is flat and most of it is covered by loose layers of Quaternary and Tertiary, forming a plain topography. The natural ground elevation is $25.50-27.00 \mathrm{~m}$, generally around $26.00 \mathrm{~m}$. The larger river in the minefield is the Hui River, which flows from the northwest to the southeast from the middle. It is a first-level tributary of the north bank of the Huai River. It originates from the eastern suburbs of Shangqiu City, Henan Province (in China). It has a total length of about $265 \mathrm{~km}$ and a drainage area of $4580 \mathrm{~km}^{2}$. The province flows through Suixi, Suxian, Lingbi and Guzhen, and enters the Huaihe River in Wuhe County. The area where the mine field is located has a warm temperate semi-humid climate with four distinct seasons, cold in winter and hot in summer. The annual average temperature is $14.4^{\circ} \mathrm{C}$, and the temperatures at the poles are $41^{\circ} \mathrm{C}$ and $-23.2^{\circ} \mathrm{C}$ respectively.

\section{Research Materials and Methods}

\subsection{Temperature Measurement Data}

In this study, there are 21 temperature measurement boreholes in the systematic collection area, of which 7 are approximately steady-state temperature measurement boreholes, covering the entire study area and can more comprehensively reflect the geothermal field characteristics of the study area. There are two categories of temperature measurement data packages:

1) Approximate steady-state temperature measurement drilling: Within 1 to 3 days after drilling, the temperature of the well fluid will gradually return to the original surrounding rock temperature 7 . Therefore, after the completion of the well, after waiting for $12 \mathrm{~h}, 12 \mathrm{~h}, 24 \mathrm{~h}$, and $24 \mathrm{~h}, 4$ consecutive temperature measurements were taken to determine the recovery curve of the formation temperature with time, and then to obtain an approximately stable original formation temperature value. This time, the approximate steady-state temperature measurement data of 7 boreholes in the study area are counted. The approximate steady-state hole temperature measurement data is shown in Table 1.

2) Simple temperature measurement hole: In the process of geological exploration, it takes a long time to conduct approximate steady-state temperature measurement of the borehole, which will affect the exploration progress to a certain extent4. The simple temperature measurement is a relatively quick and easy temperature measurement method. At present, most boreholes use this method, that is, two temperature measurements are performed at intervals of several hours after completion. This time, the simple temperature measurement data of 14 boreholes in the study area were used.

\subsection{Research Methods}

In order to obtain the geothermal gradient value of each layer and the whole hole, firstly, determine the constant temperature point, neutral point and bottom hole temperature, and then connect the constant temperature point, neutral 
Table 1. Approximately steady-state temperature value when well fluid stops.

\begin{tabular}{|c|c|c|c|c|c|}
\hline Hole & $\mathrm{t} / \mathrm{h}$ & $\mathrm{T} /{ }^{\circ} \mathrm{C}$ & Hole & $\mathrm{t} / \mathrm{h}$ & $\mathrm{T} /{ }^{\circ} \mathrm{C}$ \\
\hline \multirow{6}{*}{$63-8$} & 1 & 29.4 & \multirow{6}{*}{ 67-19 } & 1 & 33.7 \\
\hline & 13 & 33.1 & & 14 & 35.1 \\
\hline & 70 & 33.3 & & 25 & 35.2 \\
\hline & 82 & 34.6 & & 37 & 35.3 \\
\hline & 106 & 35 & & 61 & 35.4 \\
\hline & 130 & 35.6 & & 85 & 35.5 \\
\hline \multirow{6}{*}{$70-14$} & 1 & 32.3 & \multirow{6}{*}{$78-7$} & 1 & 31.6 \\
\hline & 16 & 36.3 & & 9 & 32 \\
\hline & 66 & 37.6 & & 24 & 32.2 \\
\hline & 78 & 36.8 & & 36 & 32.3 \\
\hline & 102 & 37.4 & & 60 & 32.4 \\
\hline & 126 & 37.9 & & 84 & 32.5 \\
\hline \multirow{6}{*}{ 63-22 } & 1 & 36.1 & \multirow{12}{*}{$70-12$} & 1 & 36 \\
\hline & 12 & 37 & & 16 & 37.1 \\
\hline & 24 & 37.5 & & 28 & 37.7 \\
\hline & 36 & 38 & & 40 & 38.9 \\
\hline & 60 & 38.5 & & 64 & 39.5 \\
\hline & 84 & 39.1 & & 88 & 40.7 \\
\hline \multirow{6}{*}{ 71-12 } & 1 & 34.4 & & & \\
\hline & 15 & 35 & & & \\
\hline & 25 & 35.1 & & & \\
\hline & 37 & 35.4 & & & \\
\hline & 71 & 35.4 & & & \\
\hline & 95 & 35.7 & & & \\
\hline
\end{tabular}

point, and the corrected bottom hole temperature into a broken line, then this broken line is the calibration curve4. After completing the calibration curve for the simple temperature measuring hole, the ground temperature value of a certain layer and a certain depth in the borehole can be easily found from the calibration curve, and the ground temperature gradient value of each layer and the whole hole can be calculated. According to related results, the depth of the constant temperature zone in the study area is about $30 \mathrm{~m}$, and the temperature is between $16^{\circ} \mathrm{C}-18^{\circ} \mathrm{C}$. To calibrate the simple temperature measurement is to use the bottom hole temperature $T$ measured at the last time, and calculate the temperature correction increment $\Delta T$ (Song et al., 2018; Liu et al., 2014; Liu et al., 2018; Peng et al., 2015) from the fitted curve equation according to the well fluid stop circulation time $t$, and calculate the bottom hole by the following formula Temperature $T_{0}$ : 


$$
T_{0}=T_{\text {测 }}(1+\Delta T)
$$

In the formula: $\Delta T$-correction increment.

The correction of the bottom hole temperature is the key to the correction of the simple temperature measurement curve. Based on previous studies, this paper uses approximate temperature measurement hole data to fit, and finally determines the exponential curve type.

Based on the 7 approximate steady-state holes in Xutuan coal mine, the temperature change rate of each hole is calculated, and then the corresponding calibration curve is fitted from the data of each hole. Finally, the 7 approximate steady-state hole data of Xutuan coal mine are calculated After synthesis, the correction curve of the average trend of Figure 2 is obtained and the correction curve formula of the average trend of change is obtained. According to the calibration curve of the average change trend, the simple holes 74-7, 70-9, 70-10, $72-16,74-755,81-821,74-6,72-12,74-17$ in the collected area, 75-9, 73-13, 06 View 3, 2017-1, 2019-3 as the benchmark, the time after the simple temperature measurement hole in the area (the second temperature measurement) is substituted into the calibration curve equation, and the corresponding The temperature change rate $\Delta \mathrm{T}$, the bottom hole temperature can be calculated according to formula 1 . The temperature measurement data of 14 simple temperature measurement boreholes collected in the study area are sorted out, and the average value of the geothermal gradient of each mining area in the study area is obtained (Table 2).

Table 2. Geothermal gradient value table of Xutuan coal mine.

\begin{tabular}{|c|c|c|c|}
\hline Hole number & $\mathrm{X}$ axis & $\mathrm{Y}$ axis & Geothermal gradient \\
\hline $74-6$ & $39,472,367.58$ & $3,696,275.62$ & 2.8 \\
\hline $74-7$ & $39,473,849.48$ & $3,696,299.36$ & 2.8 \\
\hline $74-17$ & $39,474,791.86$ & $3,696,317.62$ & 2.7 \\
\hline $70-9$ & $39,472,106.89$ & $3,698,224.34$ & 2.8 \\
\hline $70-10$ & $39,472,937.80$ & $3,698,227.78$ & 2.9 \\
\hline $72-12$ & $39,474,125.16$ & $3,697,236.08$ & 2.7 \\
\hline $73-13$ & $39,471,957.70$ & $3,696,746.76$ & 3.0 \\
\hline $75-9$ & $39,473,153.48$ & $3,695,795.86$ & 3.3 \\
\hline $74-755$ & $39,473,922.43$ & $3,696,051.81$ & 3.1 \\
\hline $81-82-1$ & $39,471,747.48$ & $3,692,737.11$ & 3.1 \\
\hline $72-16$ & $39,472,452.25$ & $3,697,244.99$ & 3.4 \\
\hline $06-3$ & $39,467,221.52$ & $3,698,250.204$ & 2.8 \\
\hline $2017-1$ & $39,472,339.26$ & $3,695,770.97$ & 3.2 \\
\hline 2019-3 & $39,473,489.6$ & $3,693,748.92$ & 3.1 \\
\hline
\end{tabular}




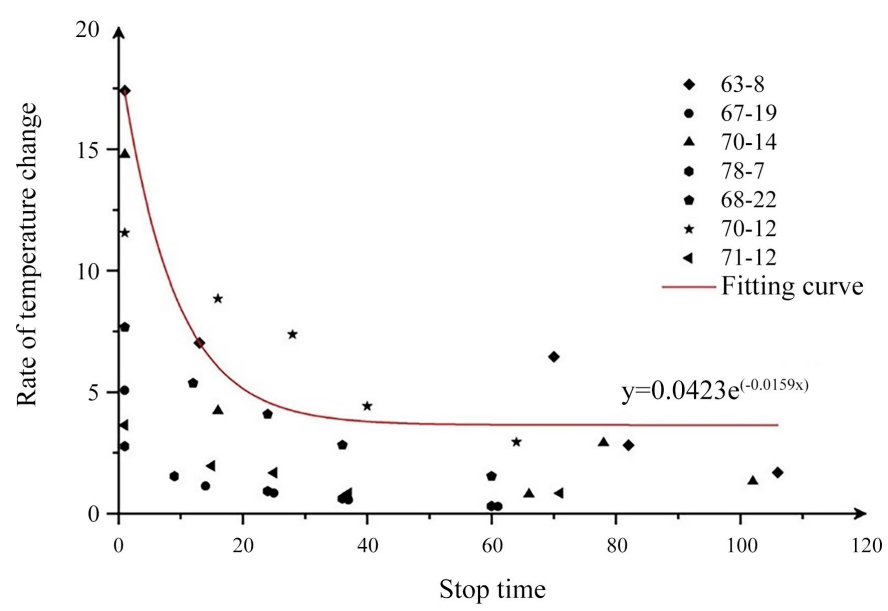

Figure 2. The correction curve of the average temperature change trend of Xutuan coal mine.

\section{Geothermal Gradient Distribution Characteristics}

In the study of ground temperature, thermal anomalies are divided into positive anomalies and negative anomalies. Anomalies above a certain temperature are positive anomalies, and vice versa. In the geothermal gradient, the distribution range of the normal geothermal gradient is $1.6^{\circ} \mathrm{C} / \mathrm{hm}-3.0^{\circ} \mathrm{C} / \mathrm{hm}$, the geothermal gradient greater than $3.0^{\circ} \mathrm{C} / \mathrm{hm}$ is a positive anomaly, and the geothermal gradient less than $1.6^{\circ} \mathrm{C} / \mathrm{hm}$ is a negative anomaly. According to the geothermal gradient value in Table 1, draw the contour map of the geothermal gradient in the study area (Figure 3). It can be seen from Figure 3 that the geothermal gradient of Xutuan coal mine varies within the range of $2.65^{\circ} \mathrm{C} / \mathrm{hm}-3.15^{\circ} \mathrm{C} / \mathrm{hm}$, most of which are $1.6^{\circ} \mathrm{C} / \mathrm{hm}-3.0^{\circ} \mathrm{C} / \mathrm{hm}$, which belongs to the normal area with relatively stable geothermal gradient. From the perspective of the plane distribution of the study area, the northern part of the study area is more developed than the southern part. The minimum geothermal gradient is $2.65^{\circ} \mathrm{C} / \mathrm{hm}$, and the ground temperature near holes $72-16,74-6$ and $75-9$ are all greater than $3.0^{\circ} \mathrm{C} / \mathrm{hm}$. The geothermal gradient gradually increases from north to south, which fully demonstrates the close relationship between geothermal distribution and structural distribution.

The relationship between the approximate steady-state temperature measurement borehole geothermal gradient and depth in the study area is shown in Figure 4.

It can be seen from Figure 4 that the geothermal gradient has a negative correlation with the buried depth within a certain depth range, and the change is minimal after the depth exceeds this depth. Roughly taking the depth of 200 $350 \mathrm{~m}$ as the dividing line, the shallow geothermal gradient value of this depth is relatively scattered, and has a negative correlation with the formation depth; beyond this depth, the geothermal gradient value changes very little, and the geothermal gradient between each borehole. The trend of decreasing with depth is slightly different. The temperature increases with the increase of depth, show- 
ing a good linear trend, showing the characteristics of conductive heating. On the whole, the current geothermal gradient decreases with increasing depth, and gradually tends to be consistent. When the depth is below $400 \mathrm{~m}$, the geothermal gradient is between $2^{\circ} \mathrm{C} / \mathrm{hm}-3.5^{\circ} \mathrm{C} / \mathrm{hm}$, while in the shallow depth range of 400 $\mathrm{m}$, the geothermal gradient is relatively discrete and higher than the geothermal gradient value below $400 \mathrm{~m}$.

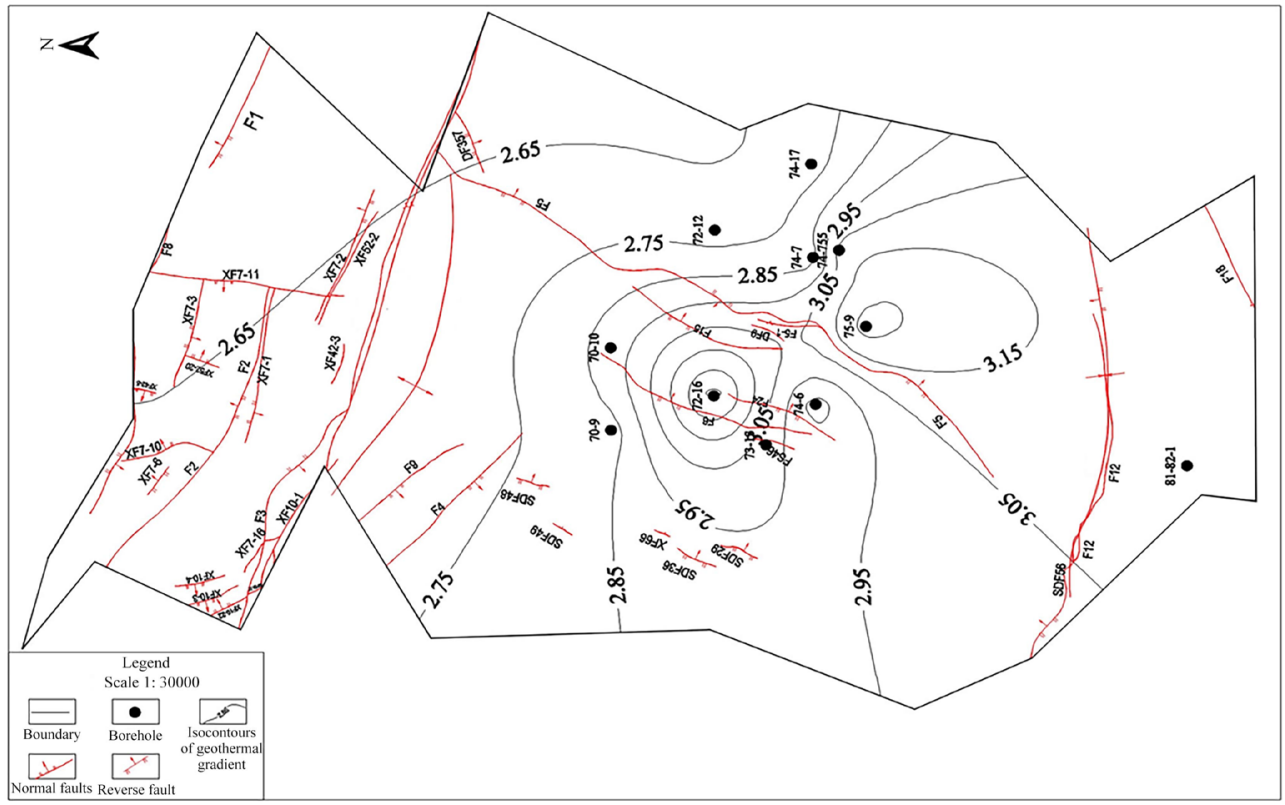

Figure 3. Geothermal gradient contour map of Xutuan coal mine.

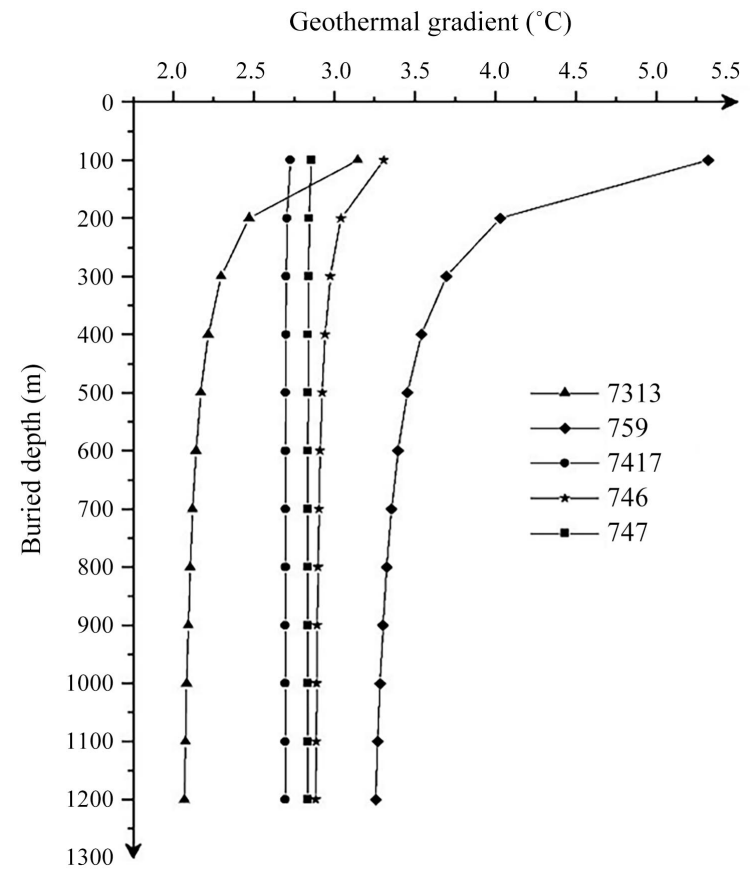

Figure 4. The relationship between approximate steady-state temperature measurement borehole temperature gradient and depth. 


\section{Control Factors of Geothermal Field}

The distribution of ground temperature is controlled and influenced by many factors, including regional geological structure, loose layer thickness, rock thermophysical properties, magmatism, and groundwater activities (Wang, 2011; Wang et al., 2019; Yang et al., 2012). Based on the distribution characteristics of the current geothermal field in the Xutuan mine and the performance of its differences in the previous article, this section focuses on the geological structure, lithology, especially groundwater activities and other factors to analyze the causes of geothermal anomalies, revealing the current geothermal field in the study area Abnormal mechanism.

\subsection{Geological Structure}

The strong geological tectonic movement can not only form folds, fractures and other structural forms, change the occurrence of rock formations, thereby causing changes in the thermophysical properties of rocks in the horizontal and vertical directions; but also cause the redistribution of heat energy deep in the earth, Thereby changing its geothermal field (Yao \& Pang, 2018; Lu, Qin, \& Guo, 2013; Zhou et al., 2017). The tectonic movement deforms the crust, folds and breaks, and forms uplifts and depressions. As a result, the thermal conductivity of the rocks in the crust changes not only in the vertical direction, but also in the horizontal direction, so that the uniform heat flow from the inside of the earth is in the shallow crust. Redistribute, as shown in Figure 5.

The upper part of the uplift area has higher ground temperature, temperature gradient and heat flow value, while the depression area is relatively low. Analyzing the distribution of ground temperature in the Huaibei coalfield (in China), the Suntuan, Xutuan, Renlou, Huagou, Wolonghu, and Huangji mining areas located around the Tongting anticline are areas with high geothermal and high geothermal gradients, and the Tongting anticline is cut by a north-east fault., Leading to the disconnection of high temperature abnormal areas in Renlou and Xutuan mining areas on both sides of the fault, indicating that large folds and fault structures in the Huaibei coal field have a certain control effect on the distribution of the geothermal field.

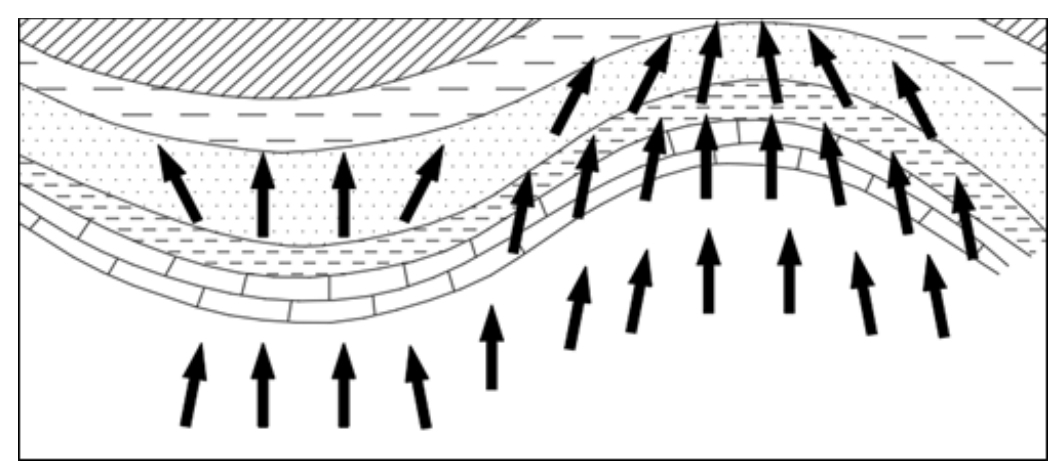

Figure 5. Heat transfer diagram of fold structure. 
The influence of faults in the Huaibei coalfield on the ground temperature is mainly reflected in the anticline uplift area where the fault structure is relatively developed, while the effect is relatively weak in the syncline depression area where the fault is not developed. The influence of faults in the Huaibei coalfield on the ground temperature is mainly reflected in the anticline uplift area where the fault structure is relatively developed, and the local ground temperature is controlled by the main affecting faults in the mine. The Xutuan and Renlou minefields are located on the two wings of the Tongting anticline. Compared with other Huaibei coalfields, they exhibit a high geothermal gradient. The two minefields are cut by anticline faults, and high temperature anomalies are separated. They are distributed symmetrically with respect to the Xutuan fault. The abnormal temperature areas in the mining area are basically distributed near the main control faults. For example, the 72-16 borehole near F6 fault has a geothermal gradient of $3.4^{\circ} \mathrm{C} / \mathrm{hm}$, and the $75-9$ borehole near F5 fault has a geothermal gradient. It shows that the fault has a certain control effect on the plane distribution of the geothermal field. The Xutuan fault is located in the northern part of the mine (the boundary of the 84 and 86 mining areas). It is a reverse fault, strikes NWW, inclines to SSW, dips $55^{\circ}-63^{\circ}$, falls 115 - $325 \mathrm{~m}$, and extends about 8100 $\mathrm{m}$. It runs through the east-west boundary of the mining area and is not water-rich. The Xutuan fault is a large-scale fault structure in the Huaibei coalfield. The Xutuan mining area on the south side of the Xutuan fault is basically within its range of influence. The mining area is controlled by the Xutuan fault. The high-angle and large faults cause the deep geothermal to move upward and improve the overall mining area. The ground temperature is expressed as the abnormally high temperature area of the Huaibei coalfield. The local geothermal anomaly in the mining area is less affected by it, and is mainly affected by the fault structure in the mining area.

\subsection{The Influence of Rock Formation Properties on the Geothermal Field}

Different types of rocks have different thermal conductivity and thermal conductivity, and some are even very different. This is the fundamental reason why lithological changes can change the distribution of geothermal field (Yan et al., 2018).

The thermal conductivity of rock formations increases with the increase of geological age. Ancient crystalline bases and older compact rocks have high thermal conductivity and low thermal resistance; overlying newer sedimentary layers, especially semi-consolidated or Cenozoic. The loose sediment has low thermal conductivity and high thermal resistance. The heat inside the earth is conducted outward through the rocks. The thermal conductivity of a rock mainly reflects how fast the rock conducts heat. Different rocks have different heat conduction capabilities. Therefore, there is a big difference in heat conduction, and the combination of different rocks has a different effect on the distribution of ground temperature. The lithology of the new and old strata in the 
study area is quite different. The upper Cenozoic strata are mainly composed of unconsolidated rocks, mostly fine sand, clay and gravel, etc., with low thermal conductivity; the Permian coal measure strata are mainly composed It is mainly composed of mudstone and sandstone with high degree of consolidation, with high thermal conductivity. Therefore, it can be seen from the graph of the relationship between the ground temperature and the depth of the study area (Figure 4) that the current geothermal gradient of the study area decreases with the increase of depth, and tends to be consistent when it reaches a depth of about $400 \mathrm{~m}$, but the current geothermal gradient at a shallower depth is significantly higher. The better thermal conductivity of the rocks in the deep coal-measure strata in the study area allows the rapid conduction of ground temperature in the deep, and the current geothermal gradient is relatively low, but the shallow cover layer with low thermal conductivity hinders heat conduction and loss, resulting in higher current geothermal gradient value.

\subsection{The Impact of Groundwater on the Ground Temperature Field}

Groundwater is the most active geological factor and a good carrier of heat. The temperature difference between it and the surrounding rock can change the temperature of the surrounding rock (Hu et al., 2019). The impact of groundwater activities on the ground temperature site can be summarized in Figure 6.

When the low-temperature groundwater moves downward, the groundwater supplied by the cold water source continuously absorbs the heat of the surrounding rock, thereby reducing the temperature of the surrounding rock, and a low temperature abnormality (Type B) occurs; When the groundwater runoff is slow or the local water moves along the isothermal surface, it will cause the temperature balance of the surrounding rock (Type C); when the deep-circulating groundwater is heated by the surrounding rock during the circulation process, and flows under favorable geological conditions, Will cause a local temperature increase in the channel and above, and the fracture is a good channel for deep hot water to migrate upwards (Type D). That is, the difference in temperature between the groundwater and the surrounding rock can increase, maintain, and decrease the temperature of the surrounding rock.

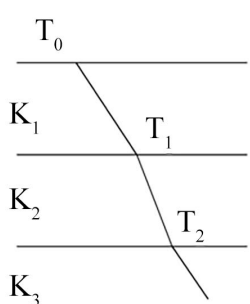

Type A

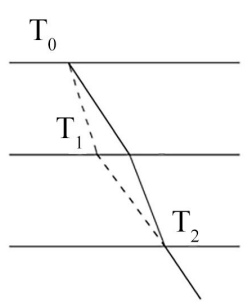

Type B

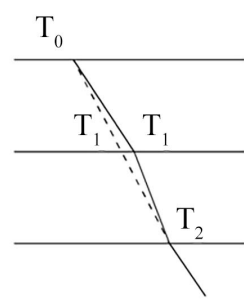

Type C



Type D

Figure 6. Schematic diagram of the influence of groundwater activities on the ground temperature field. 
Analyze the pumping test data of each aquifer in Xutuan coal mine and draw the Paper diagram (Figure 7). From Figure 7 the water chemical characteristics of the same aquifer in the mining area, such as the anion and cation concentration, salinity, PH value, and hardness, have no obvious changes. The distribution of ground temperature field has no obvious influence. The difference in water chemistry of each aquifer is more obvious, and the water chemistry characteristics of some aquifers are similar, and there may be hydraulic connections. The heat exchange between groundwater of different temperatures affects the distribution of the geothermal field at various levels in the mining area. There is a cross-flow replenishment relationship between the first and second occupants and the second and third occupants of the Xutuan coal mine. Its excretion method is mainly lateral runoff. Due to the barrier of the three partitions, the first, second, and third water content loses hydraulic connection with the fracture water of the fourth-bearing coal-measure sandstone below it. The Cenozoic IV directly covers the various aquifers of the bedrock, and is mainly supplied by regional interlayer runoff. In its natural state, there is a certain hydraulic connection with the underlying aquifers through outcrops.

According to the four-water level contour map, as shown in Figure 8, the four-bearing groundwater flows from the high water level area to the low water level area. Analyze the distribution map of the shallow geothermal field, the four water-bearing high-head areas correspond to the shallow high-temperature anomaly area, that is, the middle of the 83 lower mining area, analyze the high-temperature anomaly areas caused by the heat concentration in the four water-rich areas; the hydrodynamic conditions are strong, the flow velocity of the four water cuts from the high water level and high temperature area to the low water level area is large, and the thermal interaction with the rock is poor. The four water cuts basically have no heat loss during the flow process, and finally flow to the north of the 33 mining area. The northern part of the upper 33 mining area is the thickest area of the loose layer in the entire mining area. The heat resistance effect of the loose layer plus the surrounding four water replenishment is manifested as the high temperature abnormal area in the north of the 33 mining area, which is connected with the high temperature abnormal area in the 83 lower mining area. The long axis direction of the high temperature zone basically corresponds to the four-water flow direction, which shows that the four-water flow has a certain control effect on the shallow geothermal field distribution.

\section{Conclusion}

1) The geothermal gradient in the study area is between $2^{\circ} \mathrm{C} / \mathrm{hm}-3.5^{\circ} \mathrm{C} / \mathrm{hm}$, and the geothermal gradient gradually increases from north to south. Taking the normal ground temperature as the background as a whole, there is a local high temperature abnormal area in the northern part of Xutuan coal mine 33 mining area. 


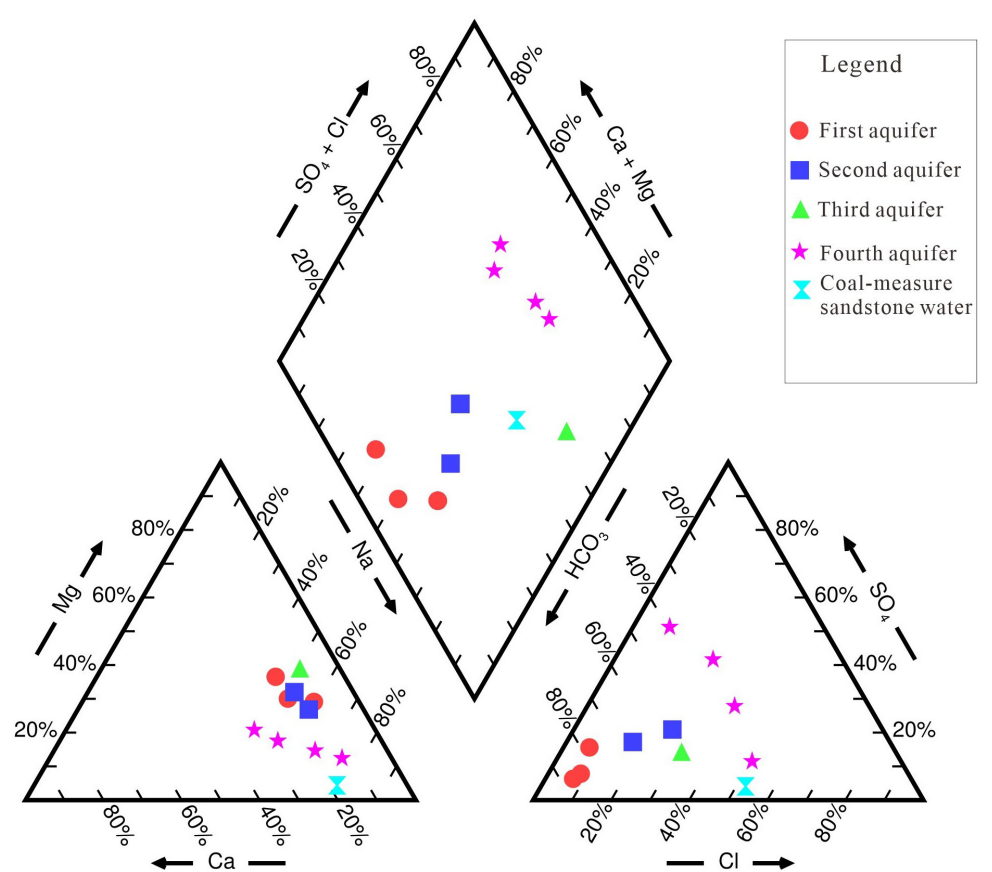

Figure 7. Paper diagram of each aquifer in Xutuan coal mine.

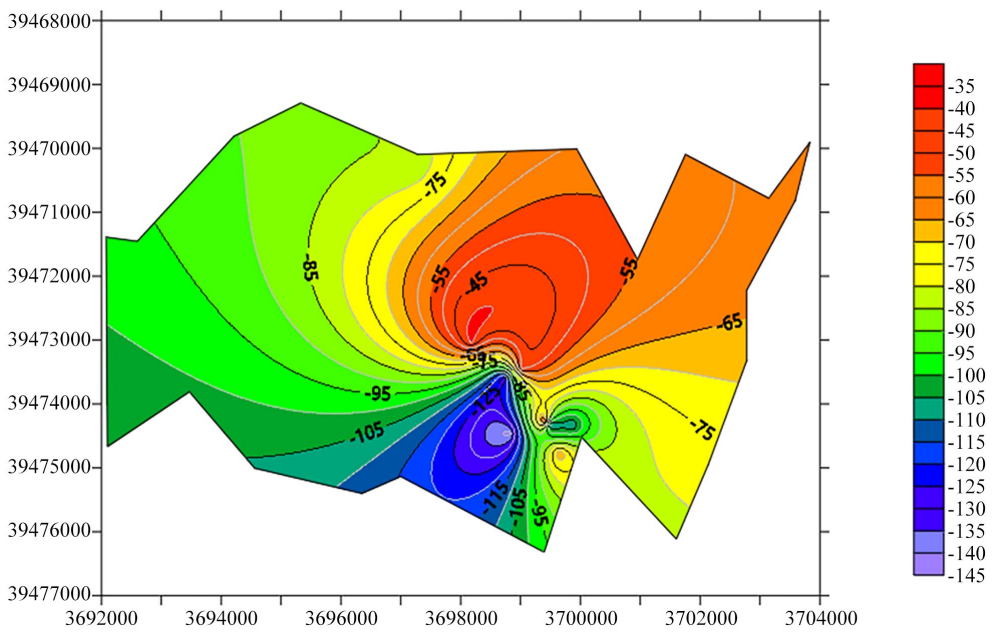

Figure 8. Contour map of the four water levels in Xutuan coal mine.

2) Vertically, the geothermal gradient has a negative correlation with the buried depth within a certain depth range, and the change is minimal after this depth. The dividing line is roughly $200-350 \mathrm{~m}$ depth. The temperature increases with the increase of depth, showing a good linear trend, showing the characteristics of conductive heating. On the whole, the current geothermal gradient decreases with increasing depth, and gradually tends to be consistent.

3) The main influencing factor of the geothermal field in the study area is the geological structure, which is greatly affected by the fault structure, followed by lithological changes and groundwater activities. Due to the recharge of the four water cuts, the high temperature abnormal area in the northern part of the 33 
mining area is connected with the high temperature abnormal area of the 83 lower mining area. The flow of the four water cuts has a certain effect on the shallow geothermal field distribution. The geothermal field in the study area is the result of the combined effects of the above factors.

\section{Conflicts of Interest}

The authors declare no conflicts of interest regarding the publication of this paper.

\section{References}

Cui, J. P., \& Ren, Z. L. (2011). Characteristics of Present Geothermal Field of the Wuerxun Depression in Hailaer Basin, Inner Mongolia. Geoscience, 25, 589-593.

Hu, S. B., Long, Z. L., Zhu, J. Z., Hu, D., Huang, Y. P. L., \& Hu, J. (2019). Characteristics of Geothermal Field and the Tectonic-Thermal Evolution in Pearl River Mouth Basin. Acta Petrolei Sinica, 40, 178-187.

Li, Y. J., \& Li, R. F. (2010). Characteristics of Present-Day Geothermal Field of Gaoyou Sag in Subei Basin. Geoscience, 24, 1042-1047.

Lin, Z. L., Xiao, P. F., Li, H., Yu, J. B., \& Lu, H. (2015). Characteristics of the Geothermal System and Control Factors in the Yalahe Each, Ganzi Area. Geology and Exploration, 51, 764-771.

Liu, D. D., Hu, A. Y., Liu, C. B., \& Huang, J. R. (2014). Study of Characteristics and Influencing Factors in a Vertical Direction of the Shallow Geothermal Field in Xi'an City. Ground Water, 36, 1-4.

Liu, J., Yang, X. P., Xu, W., Yang, X. L., \& Fang, L. (2018). Methods for Detailed Characterization of Geothermal Fields in Complex Rift Basin. Journal of Southwest Petroleum University (Science and Technology Edition), 40, 75-82.

Lu, L. L., Qin, Y., \& Guo, C. (2013). Modern Geothermal Field and Coal Seam Heating Temperature in Buzuo Exploration Area, Western Guizhou. Coal Geology of China, 25, $12-17$.

Luo, Y., Ju, Y. W., \& Tan, J. Q. (2011). Characteristics of Present Geothermal Field and Prediction of Its Thermal Damage in Suntuan-Zhaoji Exploration Area. Journal of Graduate University of Chinese Academy of Sciences, 28, 734-739.

Peng, J., Wu, J. W., \& Peng, T. (2015). Distribution Characteristics and Abnormal Factors of Geothermal Field in Linhuan Mine Area. Coal Engineering, 47, 88-91.

Peng, T., Wu, J. W., Ren, Z. Q., Xu, S. P., \& Zhang, H. C. (2015). Distribution Characteristics of Current Geothermal Field and Terrestrial Heat Flow in Huaibei Coalfield. Earth Science-Journal of China University of Geosciences, 40, 1083-1092.

Song, Y. M., Jia, Z. X., Chen, B., \& Jiang, T. C. (2018). Simple Temperature Correction and Geothermal Distribution in Panlong-Gaojiatun Investigation Area. Coal Technology, 37, 113-115.

Wang, D. (2011). Formation Mechanism of Thermal Groundwater and Characteristics of Geothermal Field in Gaoligong Mountain Dali-Ruili Railway (pp. 80-86). Chengdu: Chengdu University of Technology.

Wang, Z. T., Zhang, C., Jiang, G. Z., Hu, J., Tang, X. C., \& Hu, S. B. (2019). Present-Day Geothermal Field of Xiongan New Area and Its Heat Source Mechanism. Chinese Journal of Geophysics, 62, 4313-4322. 
Yan, Y., Zhao, G. C., Wang, X., Di, Y. L., Lai, Y., Cheng, Y. Z., Yu, H., \& Guo, Q. (2018). Tectonic Constraints on the Underground Thermal-Water Resources and Prospecting Indicators in the Ningcheng Area, Inner Mongolia. Geology and Exploration, 54, 166-173.

Yang, D. D., Wang, B. S., Zhang, X., \& Yang, P. P. (2012). Ground Temperature Distribution and Heat Damage Prevention of Huainan Coal Field. China Mining Magazine, 21, 94-97.

Yao, W. J., \& Pang, J. Y. (2018). The Status and Progress of the Research on Thermal Environment of Deep Mine in China. Mining Safety and Environmental Protection, 45, 107-111.

Zhou, Y., Mu, G. X., Zhang, H., Wang, K., Liu, J. Q., \& Zhang, Y. G. (2017). Geothermal Field Division and Its Geological Influencing Factors in Guanzhong Basin. Geology in China, 44, 1017-1026. 